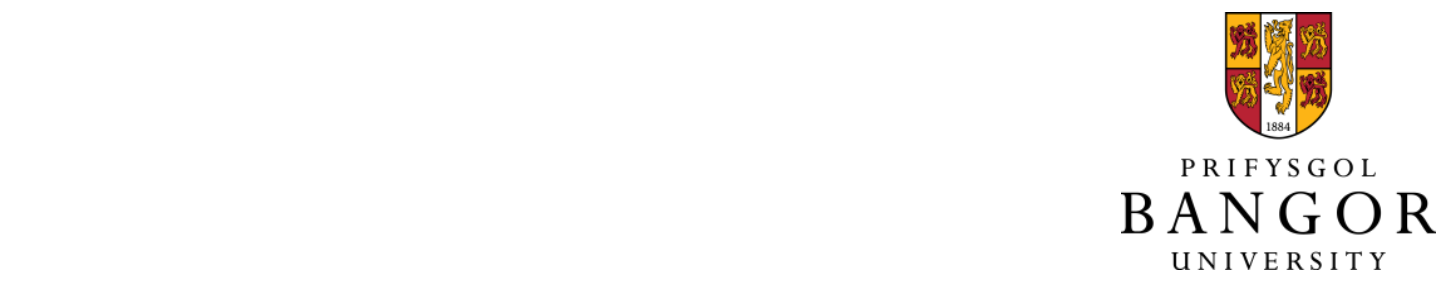

\title{
Four domains of students' sense of belonging to university
}

Ahn, Mi Young; Davis, Howard

\section{Studies in Higher Education}

\author{
DOI: \\ $10.1080 / 03075079.2018 .1564902$
}

Published: 03/03/2020

Peer reviewed version

Cyswllt i'r cyhoeddiad / Link to publication

Dyfyniad o'r fersiwn a gyhoeddwyd / Citation for published version (APA):

Ahn, M. Y., \& Davis, H. (2020). Four domains of students' sense of belonging to university.

Studies in Higher Education, 45(3), 622-634. https://doi.org/10.1080/03075079.2018.1564902

\footnotetext{
Hawliau Cyffredinol / General rights

Copyright and moral rights for the publications made accessible in the public portal are retained by the authors and/or other copyright owners and it is a condition of accessing publications that users recognise and abide by the legal requirements associated with these rights.

- Users may download and print one copy of any publication from the public portal for the purpose of private study or research.

- You may not further distribute the material or use it for any profit-making activity or commercial gain

- You may freely distribute the URL identifying the publication in the public portal ?
}

Take down policy

If you believe that this document breaches copyright please contact us providing details, and we will remove access to the work immediately and investigate your claim. 


\title{
Four domains of students' sense of belonging to university
}

\author{
Mi Young Ahn', Howard H. Davis ${ }^{\mathrm{b}}$ \\ ${ }^{a}$ Bangor University, School of Social Sciences, Bangor, UK \\ E-mail address: m.ahn@bangor.ac.uk \\ ${ }^{b}$ Bangor University, School of Social Sciences, Bangor, UK \\ E-mail address: h.h.davis@ bangor.ac.uk
}

Students' sense of belonging is known to be strongly associated with academic achievement and a successful life at university. To achieve a comprehensive understanding of belonging, this study collected data via the 10 Words Question. Responses from 426 participants were analysed using a sequence of analytic methods including In Vivo coding, systematic coding, clustering, and contingency analysis. The results show that, in addition to academic and social engagement, there are two additional domains of belonging which are often neglected: surroundings and personal space. Surroundings equate to participants' living space, and geographical and cultural location, while personal spaces refer to life satisfaction, life attitudes, identity and personal interests. Both positive and negative data demonstrate the complex and multi-dimensional character of belonging in higher education. The study concludes that policies for student engagement in higher education should reflect all four domains to support the full range of students' experiences.

Keywords: sense of belonging; higher education; engagement; 10 Words Question; education policy 


\section{Introduction}

There is a general consensus in education that sense of belonging refers to students' feelings of being accepted, included by and connected to their institutions (Goodenow 1993, 80). Tinto, for example, describes sense of belonging as 'a generalized sense of membership that stems from students' perception of their involvement in a variety of settings and the support they experience from those around them' (Tinto 2012, 66).

This belonging is positively related to various aspects of students' experiences in higher education, such as social and psychological functioning (Hagerty et al. 1996), support and caring (Freeman et al. 2007), college activities (Hurtado and Carter 1997), self-confidence and academic achievement (Pittman and Richmond 2007), and social recognition and acceptance (Freeman et al. 2007). A number of studies have also found that various elements including sense of belonging play a crucial role in student retention (e.g., Thomas 2012; Tinto 1975, 1996; Astin 1999). For instance, Tinto’s retention model concludes that academic and social integration, and institutional support are crucial factors (Tinto 1987).

Engagement has become one of the most popular terms in education research (Masika and Jones 2016; Kahu 2013; Thomas 2012). Many researchers have found that engagement is associated with students' sense of belonging, success and retention. Kuh et al. (2005) discover a strong correlation between engagement and students' success, and Baumeister and Leary (1995) reveal that concrete relationships based on regular social interaction seem to be vital to belonging in the educational context. Osterman's extensive literature review (2000) also concludes that students' academic and social engagement is vital to their reported belonging. According to Astin's (1999) theory of student involvement, students' participation levels in academic and social activities determine students' retention to a large extent. These factors refer not only to students' 
personal experiences as well as their social interactions but also to the educational environment, which influence sense of belonging and retention (Astin 1999, 529).

Several studies have attempted to explore students' sense of belonging in higher education in the UK (e.g., Read et al. 2003; Wilcox et al. 2005; Thomas 2012). Read and colleagues' (2003) qualitative study consists of three different research projects designed to understand students' perspectives on belonging to a post-1992 university ('New university'). Wilcox and colleagues (2005) conducted qualitative research with first year students studying social sciences related subjects at the University of Brighton. Their main research focus was to explore the meanings and roles of social support in relation to belonging, social integration, and retention. They highlight that 'making compatible friends' $(2005,718)$ is the most important aspiration for students who start university, which is related to academic, emotional, and social support, and affects their sense of belonging as well as, ultimately, retention.

On the nation-wide scale, there is research exploring various aspects of students' belonging in the higher education context, notably the What Works? Student Retention \& Success programme 2008-2011, co-funded by the Paul Hamlyn Foundation (PHF) and the Higher Education Council for England (HEFCE) (Thomas 2012). The findings from the What Works programme show that academic engagement is expressed through curricula and activities such as interactions between students and academic staff as well as learning and teaching experiences, while social engagement refers mainly to social relationships with friends and peers within the institutions through university clubs and societies, and other social spaces (Thomas 2012,15). It also suggests that these forms of social engagement can generate informal peer support and thus contribute to students' belonging. 
Several Higher Education Academy (HEA) studies focus on students' engagement, first-year experience, and sense of belonging in higher education. Trowler's literature review (2010) is a useful source for understanding the development of higher education research and current trends in the UK. The author argues that British researchers have tended to investigate students' experiences in teaching and learning, and points out there has been little peer-reviewed research on student engagement in the UK, where the studies are mostly in the form of grey literature (e.g. small, single case studies) like much of the American research (2010, 3). She stresses the need for further research on students' engagement in British higher education. Harvey and colleagues (2006) explore more than 750 publications from the last two decades, to identify key topics in first-year students' experiences in higher education. In this extensive literature review, they point out that the British research in higher education is inclined to focus on students' attitudes, expectations, and satisfaction $(2006,4)$.

\section{The project}

Despite the acknowledged importance of students' sense of belonging in higher education, there is a lack of theoretical and empirical research based on substantial empirical data and sensitive analytical technique. The project, Students' Sense of Belonging to [Author's] University Research, was carried out in 2014, in order to understand how students express their thoughts and feelings of belonging to the institution - a university of about 11,000 students, founded in 1884 , located in a small city in the predominantly rural area of north Wales. It was a response to the What Works? Student Retention \& Success programme 2008-2011 (Thomas 2012), which influenced this study conceptually and methodologically ${ }^{\mathrm{i}}$. 
The data was collected using a newly developed technique: the 10 Words Question (Author 2017). The 10 Words Question is a self-completion task, which asks participants to write down up to ten words which come to mind when they think about their sense of belonging to this university. Thus, engagement is not used as an a priori category in data collection. It is a simple but effective instrument to collect an extensive body of textual data, and is distinctive in being amenable to quantitative as well as qualitative analysis.

A non-random sampling strategy was used to recruit a purposive maximumvariation sample of students from the schools within the university. The sample included mature students, Widening Access students, international (non- EU) students, and students studying through the medium of Welsh. To overcome the problem of low response rates in previous research, participants were recruited within their scheduled lectures. Data was collected at the beginning of the lecture by members of the research team between the 17th March and 2nd May 2014. This project was designed to comply with the appropriate ethical guidelines and procedures for the [Author's] University, and ethical approval was obtained from the relevant Ethics Committee. ${ }^{\text {ii }}$

In total, 426 students participated, including undergraduate, master, and $\mathrm{PhD}$ students, from 14 different academic schools. Since the 10 Words Question was open to any type of response, it elicited data in two distinctive forms: words data and narrative data. Words data refers to responses in the form of a single word or short phrases, whereas narrative data refers to responses written in forms such as longer phrases, sentences, and paragraphs. The responses were divided into words data (372 participants, $87.3 \%$ ) and narrative data (54 participants, $12.7 \%$ ). The analysis follows a logical sequence of analytic methods, where the words and narrative data were analysed separately, before they were merged at the final stage. 


\section{The first stage: In Vivo coding results}

In Vivo coding is a literal record of participants' responses in their original form (Rapley 2011, 282; Strauss 1987, 33). The process was used at the first analytic stage to gather together responses with similar meanings. The total of 2,671 words data from 372 participants was examined to group them into representative words, which are core words sharing the same semantic roots. For instance, 'friendly' appeared 17 times and was appointed as the representative word; 'friendliness' was also counted, since the word came from 'friendly'. In addition, 'friendly faces', 'friendly environment', 'friendly people', ‘welcoming/ friendly', ‘societies/lecturers-friendly’ were added, because the responses contained the specific word (friendly), and also because that representative word played the key role.

This led to the consolidation of 2,072 words $(77.6 \%)$ into 133 representative words, excluding 655 words $(22.4 \%)$ which could not be coded in this stage. It would be pointless to proliferate categories for all the data at this point. Although the results did not include all of the data, they were sufficient to conduct an initial descriptive analysis at this stage. It began to reveal prominent patterns in belonging, based on the frequencies of the representative words.

The representative word 'friends' was the most frequently used word (155 times, 5.8\%); followed by 'societies' (126 times, 4.7\%). 'Societies' and 'clubs' are commonly used terms on campus, both meaning 'University clubs and societies'. They occurred 182 times altogether. It is striking that three words, 'friends', 'clubs and societies', are dominant in students' minds regarding their belonging. They account for more than 12 percent (337 times, 12.6\%) of the entire words data; and more than one in four participants (26.6\%) bring up these words as the first response, when they think about their sense of belonging to this university. 
The majority of representative words (113 representative words, 85.0\%) are nouns, while the rest (20 representative words) are adjectives and adverbs, such as friendly, involved, happy, connected, together, academic, international, included, separate, and beautiful. Some words describe actions and behaviours such as socialising, drinking, attending, or running, while others are related to emotional status such as happy, fun, welcoming, pride, and isolated. Words relating to the natural environment were also found: rain, hill, sheep and sea.

Some words are concrete nouns such as 'sports, mates, library, family, lecturer, and exams'. Others are abstract (e.g. independence, atmosphere, and knowledge), or generic (e.g. participation, opportunity, and accessible) ${ }^{\mathrm{iii}}$. When the meanings of words are less straightforward or concrete, they are interpreted in the context of other expressions in the response sheets.

[Figure 1. Results of In Vivo Coding with 133 representative words as a Word Cloud ${ }^{\mathrm{iv}}$ ]

The visualization using word cloud software in Figure 1 clearly highlights the prominence of certain words, namely representative words and others which describe social aspects of students experience such as 'sports', 'friendship', and 'support'. On the other hand, and equally noticeable, is the large number of other words with low frequencies and high dispersion, showing how complex is the sense of belonging.

Most representative words seem to refer to social aspects of students' life, whereas words related to academic engagement are less prominent. The words directly and indirectly related to academic engagement include lectures (52 times), work (34), study (23), education (22), library (21), learning (20), lecturer (20), tutorials (19), 
degree (14), school (13), seminar (12), research (11), and tutorials (10). The sum of the frequency counts is $352(13.2 \%)$, and occurrences as the first word is $45(12.1 \%)$.

This result raises an interesting question about the assumed salience of academic engagement; academic-related words are found less often than might be expected from the review of previous research, where academic engagement has been assumed to be a prominent aspect of students' sense of belonging to higher education institutions. Compared to three representative words of 'friends', and 'clubs and societies' (337 times, $12.6 \%$ ), the sum of frequency of academic words (352 times, 12.1\%) is less than expected. Nevertheless, more than one in ten participants came up with one of these words as the first word.

At this first stage of analysis, it is notable that social engagement is one of the most conspicuous factors in students' sense of belonging. This finding is confirmed repeatedly throughout this study.

\section{The second stage: systematic coding results}

At the second stage, systematic coding was applied to the entire dataset ${ }^{\mathrm{v}}$ using a thesaurus technique, based on synonyms and common-sense understandings. Systematic coding resulted in 82 representative words. 'Society' (societies) is the most frequent representative word (289 times, $10.8 \%$ ), followed by 'lecture' (226 times, 8.5\%), 'friends' (149 times, 5.6\%), 'pubs' (102 times, 3.8\%), 'halls' (85 times, 3.2\%), and 'happy' (82 times, 3.1\%). These six representative words account for more than one third of the whole data (34.9\%), while the remainder consists of 76 representative words.

Social engagement appears to be more salient than academic engagement, since representative words related to social aspects are more visible than academic activities. 
Some words belong to neither category, such as 'natural environment', 'happy', 'halls', 'local', 'student', and 'hobby'.

Whereas the In Vivo coding was designed to keep the original data intact and the representative words were chosen for their literal, primary definition, the second stage of systematic coding was used to identify patterns and themes. This resulted in fewer representative words with more general and implicative meanings. Although fewer, the number of representative words was still quite large. The next stage involved a further reduction through clustering.

\section{The third stage: clustering and thematic analysis results}

For this stage, five rules were applied to categorise the 82 representative words into themes with genuine consistency and homogeneity. The representative words with similar meanings were gathered together (the relevance rule), while words with contrasting meanings were distinguished (the differentiation rule). Non-identical, but similar words generated a theme (the proximity rule). Clustering was performed in the context of higher education (the context rule), aiming to subsume all the data under the themes (the comprehensiveness rule).

After the thematic analysis of 28 categorises, there were four conceptually independent domains: academic and social engagement, surroundings, and personal spaces. Table 1 describes how these four domains were derived from 28 categories through thematic analysis and clustering.

[Table 1 Four domains of belonging with sub-domains and categories]

Several features stand out. Firstly, the domain of social engagement appears more dominant and complicated than the academic domain. Students' sense of 
belonging within the social sphere has many strands; from social and civic participation through the medium of informal and formal groups at the university, to social relations at more general and more personal levels. It ranges from emotional involvement (e.g. solidarity) to communication methods (e.g. IT skills and SNS). The social engagement domain contains the largest proportion of the words data (1,289 words, 49.3\%). Secondly, it is noticeable that the domain of Surroundings consists of a wide range of meanings such as natural, environmental, physical, cultural, and local surroundings. Lastly, students' personal space explains important elements including their attitudes, recognition, and feelings about themselves as well as their general satisfaction with life. These two domains, Surroundings and Personal space, are less often mentioned in the existing literature on students' belonging in higher education, despite their significance in this dataset.

Next, the data was re-coded to examine the frequency of four domains by participants. As Table 2 shows, 351 participants (94.4\%) wrote down one or more words from the social engagement domain; followed by 263 participants (70.7\%) from the academic engagement. Although the number of participants who mentioned academic engagement was quite high, social engagement aspects were the most frequently occurring. In addition, two other domains, Surroundings and Personal space appeared equally important, judging by frequency of mentions $(51.1 \%$ for Surroundings, and $56.5 \%$ for Personal spaces).

[Table 2. Descriptive analysis results of the words data for four domains]

\section{The fourth stage: merging data \& contingency analysis}

To keep methodological consistency, the previous analytic procedure for the words data 
was applied identically to the narrative data (54 participants). The narrative data was coded by extracting keywords from the responses, which became representative words. For example, a participant wrote down two sentences in the response sheet, where several words related to communication were found such as 'phone', 'texts', 'facebook' and 'email'; 'I feel connected to my friends by phone + texts. I receive all the info I need from clubs/socities on facebook + email ${ }^{\text {vi }}$.

This systematic coding led to 52 representative words, which were fitted to the existing 82 representative words from the words data, except one, 'student nurse'. Eight participants (14.8\%) deliberately described themselves as a student nurse. The results of the narrative data analysis turned out to be consistent, to a large extent, with the words data.

Words and narrative data were merged and analysed by frequency. Table 3 reveals that most participants (397 participants, 93.2\%) mentioned at least one word related to social engagement; followed by academic engagement (300 participants, $70.4 \%)$. Social engagement is the most frequently mentioned aspect of students' sense of belonging to their institution. However, the combination of social and academic engagement is important: 280 participants $(65.7 \%)$ mention both academic and social engagement, and almost all participants $(98.1 \%)$ respond with either academic or social engagement. Two domains, Surroundings and Personal space are also mentioned by around half of the participants (48.8\% and 55.6\%). More importantly, these results remained consistent throughout the analytic stages.

[Table 3. Descriptive analysis results of the merged data for four domains] 
Contingency analysis was performed to explore the interrelationships between these main domains. The 'association structure' of the data is examined by applying cross-tabulation analysis, where contingency is defined as 'co-occurrences of symbols' (Osgood 1959, 109). The contingency analysis of four domains from the merged data confirms that they are independent from each other ${ }^{\mathrm{vii}}$. The results of this analysis show that there is no significant association between all six cases of any two domains.

\section{Negative data}

During the analysis of words and narrative data, a substantial number of negative responses were discovered. For this study, 'negative data' refers to data which either includes any negative expression or has an implied negative meaning. There are 43 instances of the former, in responses such as 'lack of', 'not enough', or 'no'. Words which are negative by implication, include 'isolated' (27 times), 'stress' (22), and 'unhappy’ (21).

The frequency of negative words is $113(4.2 \%)$ out of the total of 2,614 words data. The frequency of participants who wrote down one or more negative responses is $62(16.7 \%)$. The average number of negative words per participant is 1.8 words. The descriptive analysis reveals that 38 participants (62.3\%) use only one negative response, while the range of negative data per participant is from 1 to 8 . There are 22 representative words equivalent to $26.8 \%$ of 82 representative words. Apart from three representative words, 'isolated' (27 times), 'stress' (22), and 'unhappy' (21), financial issues ('money', 9 times) seem to be the biggest concern for students, followed by heavy workloads ('work', 6) and services and facilities provided by the university ('service', 6). 
[Table 4. Negative words data and their domains with frequency]

As Table 4 reveals, the 22 words which represent negative responses in the words data are spread over the four domains of belonging. Negative words seem to be particularly closely related to the personal space domain, especially regarding life satisfaction.

Amongst the total of 54 participants in the narrative data, 26 (48.2\%) gave negative responses. For instance, although 'university' is one of the most frequent words (15 participants), it is negatively described by 11 participants $(73.3 \%)$ such as: 'This is the university I need, not that I deserve'; 'No attachment to university'; 'As a student nurse, I don't feel a sense of belonging to the university'. Other representative words such as 'belonging' (9 out of 14), 'isolated' (12 out of 12), 'service' (5 out of 12) are also mentioned. The negative responses were coded as 14 representative words (26.9\%) out of 52 representative words in total. 'Isolated' (12 times), 'university' (11) and 'belonging' (9) are most frequently mentioned by participants. The narrative responses reveal more complicated meanings of belonging, since some responses contain mixed or puzzling expressions.

Among the 88 participants $(20.7 \%)$ who wrote down negative responses, the proportion of negative responses per participant varies. However, the descriptive analysis of negative data by academic schools reveals that out of the total of 88 participants, about one third (27 participants, 30.7\%) belong to a single academic school. Participants in this academic school (75.0\%) have a strong tendency to provide negative data on personal $(83.3 \%)$, social $(80.6 \%)$ and academic $(75.0 \%)$ matters.

Since the 10 Words Question was oriented towards positive responses based on the understanding that belonging has positive attributes, the discovery of students' 
dissenting, dissatisfied, and pessimistic responses should be highlighted. The narrative form seems more suitable than single words to accommodate criticisms or complaints.

\section{Discussion}

The analysis of both words and narrative data from the 10 Words Question revealed the complexity of sense of belonging. Firstly, the analysis confirmed that academic and social engagement are important for students' belonging to their institutions, as discussed in the existing literature (e.g. Tinto 1987, 1996; Astin 1999; Osterman 2000; Thomas 2012). According to the present study, social engagement was the most salient factor, since the representative words relating to social engagement such as 'societies' and 'friends' appear consistently dominant through the analytic stages. This result is consistent with the arguments of Pittman and Richmond (2007) and Wilcox and colleagues (2005), that positive social interaction is one of the fundamental requisites for sense of belonging; as well as for success in college life. Other research typically supports this finding, as for instance, in studies concerned with regular social interactions with peers and perceived support from them (Baumeister and Leary 1995); various forms of social interaction and activities (Thomas 2012); perceived support from peers and faculty (Hoffman et al. 2002); perceived support and caring (Freeman et al. 2007), and participation in college activities (Hurtado and Carter 1997).

Secondly, the study revealed that there are two more significant domains, namely surroundings and personal spaces. Surroundings equate to participants' living space, and geographical and cultural location, while personal spaces refer to life satisfaction, life attitudes, identity and personal interests. These two domains were uncovered by the sequential analysis of the 10 Words data, and the four domains were statistically confirmed to be independent, and different from each other. 
The domain of surroundings refers to a wide spectrum of locational references which come from participants' experiences of living in the geographical, environmental, and cultural contexts of the university. It includes students' physical living spaces such as accommodation, flats, and halls, but also expands to the geographic location, the natural environment, and cultural milieu. The geographic location is signalled by locality references, such as the names of specific places ('[The City]', '[The City Pier]', 'Hills'), and the natural environment including 'mountains', 'countryside', 'sheep', and 'rain'. The cultural aspects are reflected in words like 'Wales', 'dragons', and 'Welsh(ness)'. Not surprisingly, it echoes many of the themes which are highlighted in the university's own promotional material ${ }^{\text {viii }}$.

Participants' thoughts on this theme can also be found in the narrative data;

'[The city] is very different when students go home, it is much better and lively when students are here.'

'similarity of [the city] to where I live'

'This 'place' organises intellectual and social events to provide you the opportunity to meet people and network.'

'Being a student of University, I feel connected with not only the uni, but also the rich cultural heritages of Wales.'

These elements seem to be one of the important factors influencing students' sense of belonging, as more than half of the total participants mentioned one or more words related to surroundings in this study. This finding aligns with the importance of cultural, geographical, and natural factors in the higher education context, especially regarding students' decision to select their institutions in Wales (Hinton 2011; Donnelly and Evans 2016). 
University is primarily understood as an institution providing educational services where teaching and learning activities occur. Interestingly, the present study shows that students tend to expand the meaning beyond the functional definition, considering university as home, far more than physical buildings or a geographical location. With emotional engagement to the space and imaginative value added, university becomes their temporary home to some students (Lingard et al. 2007; Barnett 2013). This process is described as the poetics of space in Bachelard's (1964) term. It is strongly related to students' identity, experiences and personal stories, developed from their own cultural and historical backgrounds, which establish the sense of space (Massey 1994, 2005; Richardson 2018). University, therefore, as a teaching and learning environment as well as home may be re-interpreted differently by individual students (Torres-Olave 2012). Despite its importance in relation to belonging, there is a lack of research on how students perceive and interpret university as a physical, symbolic and emotional place in terms of teaching and learning in higher education (Jamieson et al. 2000).

Antonsich (2010) argues that sense of belonging, the feeling of being comfortable and secure, is profoundly rooted in attachment to a certain place. Participants' responses about surroundings are expressed in terms of geographical, environmental, and cultural aspects, both within as well as beyond the boundary of the university in this study; from their living spaces to the local area, including natural and cultural environments. The domain of surroundings, therefore, is striking evidence that place attachment should be considered an important aspect of students' belonging in higher education.

The finding of the new domain of surroundings in this study can be interpreted in line with sociological perspectives. The literature about belonging shows that much 
existing research in higher education in the UK tends to understand students' belonging as an individual's subjective feeling, focusing on their success and retention within the institution. In contrast, sociological perspectives highlight the importance of the relational aspects, where belonging is interpreted as a relationship or a linkage between a person and the society. (e.g. Antonsich 2010, 645; Yuval-Davis et al. 2005, 526; May 2011, 368). To reconcile these differences, sense of belonging and its associated concepts such as a person's identity, their connection with others as well as surrounding areas such as neighbourhood and local places are explored simultaneously (e.g. May 2011; Leach 2002).

The last domain, personal spaces, in contrast, represents the psychological aspects of belonging in higher education, where the main focus is often on the individual's subjective feeling (e.g. Goodenow's (1993) 'Psychological Sense of School Membership' (PSSM), Hoffman and colleagues’ (2002) ‘Sense of Belonging Instrument' (SB instrument), Hagerty and colleagues' (1996) 'Sense of Belonging Instrument' (SOBI)). The results of the present study show that this domain consists of several elements such as students' self-esteem and identity, life satisfaction and attitudes, and personal interests. It is clearly evident that students' understandings of who they are, what they do, how much value they put on their experience, and how satisfied they are as a student, are fundamental to their belonging.

Next, the negative data from the 10 Words analysis also reveals how complicated the character of belonging is. Although 'belonging' is intrinsically a positive concept, one in five participants $(20.7 \%)$ wrote down at least one negative response. Negative data was mainly identified in the domain of personal spaces such as 'isolated', 'stress', 'unhappy', but also in academic engagement as 'university'. A literature review of student's stress in higher education research reveals that issues 
related to students' mental health and wellbeing have rapidly increased not only in the UK, but also in many other countries (Robotham 2008, 742). A student survey reported in the Guardian shows that $87 \%$ of first year students suffer from stress for academic, social and financial reasons (Wakeford 2017). This co-occurrence of positive and negative responses in one person helps to explain the complexity of belonging from both angles. It aligns particularly well with Christie et al.'s research on ambivalence about students' experience in entering higher education (Christie et al. 2008, 579). The 10 Words Question can effectively capture the multiple meanings of belonging, which are complicated and perplexing to some participants.

The findings of the negative data strongly support some previous research which is designed to explore students' experiences in higher education in the UK (e.g. Beard et al. 2007; Denovan and Macaskill 2013). Qualitative research focusing on the emotional engagement of 431 Leisure Management students revealed that students' negative experiences included worries about various changes in the university life, academic stress, and loneliness (Beard et al. 2007, 243). Another study about the transition to higher education also highlighted students' difficulties in academic, social, and personal life (Denovan and Macaskill 2013, 1016). These negative experiences and feelings are significantly related to a lack of belonging and social isolation. The concept of alienation (e.g. Seeman 1959) is often applied to understand the opposite to belonging, in the wider sense of being powerless, or meaningless (Heaven and Bester 1986; Mann 2001). Mann argued that this feeling of being less engaged, less related, and isolated in a classroom situation can be reduced by improving communication in the educational environment (Mann 2005). Similarly, a study of students' satisfaction and dissatisfaction in higher education in the UK highlighted the importance of communication regarding their teaching and learning experiences (Douglas et al. 2015). 
Communication in the higher education context is related to how students connect and interact with others such as peers, academic staff and university institutions, as shown in the present study.

The analysis of narrative data led to some additional findings. The representative words from the narrative data contain numerous negative responses. While negative responses are less visible in the words analysis, it is striking that around half of the participants who responded with narrative data expressed. These unexpected findings prompted further investigation of the negative data, which suggested that certain subgroups of participants were more likely to offer negative responses. They point to the importance of the vocational dimensions of higher education and the anticipated benefits for identity and solidarity of undertaking qualifying training in professions such as teaching, nursing and social work. The vocational dimension is defined as a students' attachment or commitment to a profession or occupation based on their academic discipline, recognition of qualification and career aspirations. It supports Robotham's finding that students' stress in higher education remains an enduring theme in vocations such as medicine, nursing and law $(2008,743)$. In addition, it aligns with previous research showing that belonging is likely to be expressed and interpreted differently by groups of students in certain disciplines including medicine (Arulampalam et al. 2007), nursing (Wray et al. 2014) and engineering (Holmegaard et al. 2014). However, there is lack of conceptual and empirical evidence to understand how professional attachment and commitment functions, and how it relates to other relevant concepts such as satisfaction, belonging, participation, and engagement in a broader range of academic disciplines in higher education (Robotham 2008). Vocational dimensions are less developed in most measurement instruments of belonging in higher education due to the weakness of the conceptual foundation and the difficulties of evaluation. 
Although the analysis in this study has provided compelling evidence to show the multi-dimensional aspects of belonging in higher education, it can be improved in future studies with data derived from demographic questions. It will be useful to explore factors which might influence participants' positive or negative responses, and variables such as gender, ethnicity, age, and socio-economic status which might be associated with the two additional domains of Surroundings and Personal space.

\section{Conclusion}

The results of this study indicate strongly and consistently that students' sense of belonging to university is multi-dimensional, although social engagement is the most salient factor. Existing research into students' belonging in higher education has a strong tendency to focus on academic and social engagement, but this study has identified two more emerging themes: Surroundings and Personal space. Surroundings refers to geographic locations, natural environments, living spaces, and cultural aspects, while Personal space refers to the domain of self-identifications, self-esteem, and life satisfaction. The contingency analysis provides confirmation that the four domains are independent of each other. This result poses a fundamental challenge to existing research on students' belonging, because it suggests that the phenomenon is more complex and multi-dimensional than current ideas allow. This study also brings more nuanced understandings of students' ambivalent attitudes towards their belonging, as discussed in relation to negative data such as stress, alienation and dissatisfaction. They suggest new lines of research on students' experiences, engagement and retention in higher education.

The findings also provide a basis for practical efforts to enhance students' success and wellbeing, by suggesting which factors are most important for the sense of 
belonging to higher education institutions in the UK. They indicate that students' experiences are more differentiated along social lines, and have more subtle connections to the institutional setting than assumed in previous studies. We conclude that policies for student engagement in higher education should reflect all four domains to support the full range of students' experiences. For instance, in addition to existing activities focusing on students' social engagement (e.g. peer guides, ambassadors, mentoring, clubs and societies), the university needs to develop initiatives which encourage students' engagement with geographical, natural, and cultural surroundings such as participating in local community events and volunteering. More approachable and effective student services (e.g. counselling and drop-in centre) providing prompt and systematic responses to complaints and suggestions are a priority. If students' belonging is to be used to promote academic success and retention, more conceptually refined approaches and empirically detailed evidence will be required.

Acknowledgement

Student's Sense of Belonging to Bangor University in 2014 was financially supported by Bangor University's Widening Access Fund (2013 - 2014). We would like to thank the student engagement office in Bangor University for support. We are also grateful to anonymous reviewers for their comments on an earlier version of the manuscript.

\section{References}

Author 2017. Details withheld for peer review

Antonsich, M. 2010. "Searching for belonging-an analytical framework", Geography Compass 4(6): 644-659.

Arulampalam, W., Naylor, R. A., and Smith, J. P. 2007. "Dropping out of medical school in the UK: explaining the changes over ten years", Medical Education 41(4), 385-394. 
Astin, A. W. 1999. "Student involvement: A developmental theory for higher education", Journal of College Student Development 40(5): 518-529.

Bachelard, G. 1964. The Poetics of Space. Boston (Mass.): Beacon Press.

Barnett, R. 2013. Imagining the University. London: Routledge.

Baumeister, R. F. and Leary, M. R. 1995. "The need to belong: desire for interpersonal attachments as a fundamental human motivation", Psychological Bulletin 117(3), 497-529.

Beard, C., Clegg, S. and Smith, K. 2007. "Acknowledging the affective in higher education", British Educational Research Journal 33(2), 235-252.

Christie, H., Tett, L., Cree, V. E., Hounsell, J., and McCune, V. 2008. ““A real rollercoaster of confidence and emotions': Learning to be a university student”, Studies in Higher Education 33(5), 567-581.

Denovan, A. and Macaskill, A. 2013. “An interpretative phenomenological analysis of stress and coping in first year undergraduates", British Educational Research Journal 39(6), 1002-1024.

Donnelly, M. and Evans, C. 2016. "Framing the geographies of higher education participation: Schools, place and national identity”, British Educational Research Journal 42(1), 74-92.

Douglas, J. A., Douglas, A., McClelland, R. J., and Davies, J. 2015. "Understanding student satisfaction and dissatisfaction: an interpretive study in the UK higher education context", Studies in Higher Education 40(2), 329-349.

Freeman, T. M., Anderman, L. H., and Jensen, J. M. 2007. "Sense of belonging in college freshmen at the classroom and campus levels", The Journal of Experimental Education 75(3), 203-220.

Goodenow, C. 1993. "Classroom belonging among early adolescent students relationships to motivation and achievement", The Journal of Early Adolescence 13(1), 21-43.

Hagerty, B. M., Williams, R. A., Coyne, J. C., and Early, M. R. 1996. "Sense of belonging and indicators of social and psychological functioning", Archives of Psychiatric Nursing 10(4), 235-244.

Harvey, L. and Drew, S. 2006. The first-year experience: a review of literature for the higher education academy. York: Higher Education Academy. 
Heaven, P. C. and Bester, C. 1986. "Alienation and its psychological correlates", The Journal of Social Psychology 126(5), 593-597.

Hinton, D. 2011. “Wales is my home': higher education aspirations and student mobilities in Wales", Children's Geographies 9(1), 23-34.

Hoffman, M., Richmond, J., Morrow, J., and Salomone, K. 2002. "Investigating 'sense of belonging' in first-year college students", Journal of College Student Retention: Research, Theory \& Practice 4(3), 227-256.

Holmegaard, H. T., Madsen, L. M., and Ulriksen, L. 2014. “A journey of negotiation and belonging: understanding students' transitions to science and engineering in higher education", Cultural Studies of Science Education 9(3), 755-786.

Hurtado, S. and Carter, D. F. 1997. "Effects of college transition and perceptions of the campus racial climate on Latino college students' sense of belonging”, Sociology of Education 70(4), 324-345.

Jamieson, P., Fisher, K., Gilding, T., Taylor, P. G., and Trevitt, A. C. F. 2000. "Place and space in the design of new learning environments", Higher Education Research \& Development 19(2), 221-236.

Kahu, E. R. 2013. "Framing student engagement in higher education”. Studies in higher education 38(5), 758-773.

Kuh, G. D., Kinzie, J., Schuh, J. H., and Whitt, E. J. 2005. Assessing conditions to enhance educational effectiveness. Jossey-Bass: San Francisco.

Leach, N. 2002. "Belonging: Towards a theory of identification with place", Perspecta $33,126-133$.

Lingard, B., \& Gale, T. (2007). "The emergent structure of feeling: what does it mean for critical educational studies and research?", Critical studies in education 48(1), 1-23.

Mann, S. J. 2001. "Alternative perspectives on the student experience: Alienation and engagement", Studies in higher education 26(1), 7-19.

Mann, S. J. 2005. “Alienation in the learning environment: a failure of community?", Studies in Higher Education, 30(1), 43-55.

Masika, R., and Jones, J. 2016. "Building student belonging and engagement: insights into higher education students' experiences of participating and learning together", Teaching in Higher Education 21(2), 138-150 
Massey, D. 1994. Space, Place and Gender. Minneapolis: University of Minnesota Press.

Massey, D. 2005. For Space. London: Sage.

May, V. 2011. "Self, belonging and social change", Sociology 45(3), 363-378.

Osgood, C. K. 1959. "The representational model and relevant research methods". In Trends in content analysis, edited by de Sola Pool, I. Urbana: University of Illinois Press.

Osterman, K. F. 2000. "Students' need for belonging in the school community”, Review of Educational Research 70(3), 323-367.

Pittman, L. D. and Richmond, A. 2007. “Academic and psychological functioning in late adolescence: The importance of school belonging", The Journal of Experimental Education 75(4), 270-290.

Rapley, T. 2011. "Some pragmatics of data analysis". In Qualitative Research Practice, edited by Silverman, D. London: Sage.

Read, B., Archer, L., and Leathwood, C. 2003. "Challenging cultures? Student conceptions of 'belonging' and 'isolation' at a post-1992 university", Studies in Higher Education 28(3), 261-277.

Richardson, J. 2018. Place and Identity: The Performance of Home. Routledge.

Robotham, D. 2008. "Stress among higher education students: towards a research agenda", Higher Education 56(6), 735-746.

Seeman, M. 1959. “On the meaning of alienation", American Sociological Review 24(6), 783-791.

Strauss, A. L. 1987. Qualitative analysis for social scientists. Cambridge University Press.

Thomas, L. 2012. Building student engagement and belonging in higher education at a time of change. Paul Hamlyn Foundation.

Tinto, V. 1975. "Dropout from higher education: A theoretical synthesis of recent research", Review of Educational Research 45(1), 89-125.

Tinto, V. 1987. Leaving college: Rethinking the causes and cures of student attrition. ERIC.

Tinto, V. 1996. "Reconstructing the first year of college", Planning for Higher Education 25(1), 1-6. 
Tinto, V. 2012. Completing college: Rethinking institutional action. University of Chicago Press.

Torres-Olave, B. M. 2012. "Imaginative geographies: identity, difference, and English as the language of instruction in a Mexican university program", Higher Education 63(3), 317-335.

Trowler, V. 2010. Student engagement literature review, Higher Education Academy. https://www.heacademy.ac.uk/system/files/studentengagementliteraturereview_ 1.pdf (accessed 22 February 2018).

Wakeford, J. 2017. "It's time for universities to put student mental health first", The Guardian, September 7. Accessed 1 March 2018.

https://www.theguardian.com/higher-education-network/2017/sep/07/its-timefor-universities-to-put-student-mental-health-first

Wilcox, P., Winn, S., and FyvieGauld, M. 2005. "'It was nothing to do with the university, it was just the people': the role of social support in the first year experience of higher education", Studies in Higher Education 30(6), 707-722.

Wray, J., Aspland, J., and Barrett, D. 2014. "Choosing to stay: looking at retention from a different perspective”, Studies in Higher Education 39(9), 1700-1714.

Yuval-Davis, N., Anthias, F., and Kofman, E. 2005. "Secure borders and safe haven and the gendered politics of belonging: Beyond social cohesion", Ethnic and Racial Studies 28(3), 513-535.

Table 1. Four domains of belonging with sub-domains and categories

Table 2. Descriptive analysis results of the words data for four domains

Table 3. Descriptive analysis results of the merged data for four domains

Table 4. Negative words data and their domains with frequency

Figure 1. Results of In Vivo Coding with 133 representative words as a Word Cloud. 
${ }^{i}$ The current study applies the concept of academic and social engagement as specified by Thomas' What Works programme (2012), It resembles Tinto's $(1975,107)$ concept of academic and social integration, and both are widely recognised in higher education research in the USA (e.g. Tinto, Kuh, Osterman), the UK (e.g. Trowler, Thomas) and other countries (e.g. the Netherlands and New Zealand). However, in some other contexts (e.g. Australia), social engagement might be conceptualised and applied differently.

ii Participants were given an information sheet with a consent form and the choice to opt out at any time without giving a reason. The data was anonymised and stored on a secure, encrypted and password protected university server. [Do you have the information to say what the response rate was?]

iii The expressions such as 'abstract' and 'generic' are used in their literal sense to describe the characteristics of the data; 'abstract' as 'existing in thought or as an idea but not having a physical or concrete existence' and 'generic' as 'characteristic of or relating to a class or group of things; not specific' (https://en.oxforddictionaries.com/).

${ }^{\text {iv }}$ In order to present the results of the In Vivo coding, the programme, 'Word It Out' (http://worditout.com/) was used. Amongst existing word clouds generators, which can create various visual formats, it was the only one compatible with the Excel data. When the raw data was provided with the selection of colour, font sizes, and font styles, this web-based programme generated the results shown. The sizes of words are proportionally calculated based on frequency, while their location is random. It is an effective tool to visualise 133 representative words in one snapshot. 
${ }^{v}$ A total of 57 words responses were either impossible to decipher because of illegibility, misspellings, or content which was too obscure to put into meaningful categories. They were marked separately as residual data.

vi 'Socities' is the literal record from the response sheet.

vii A chi-square test was performed and no relationship was found:

1. between academic and social engagement, $\chi 2(1, \mathrm{~N}=426)=0.03, \mathrm{p}=0.86$.

2. between academic engagement and surroundings, $\chi 2(1, \mathrm{~N}=426)=0.92, \mathrm{p}=0.33$.

3. between academic engagement and personal spaces, $\chi 2(1, \mathrm{~N}=426)=3.78, \mathrm{p}=0.05$.

4. between social engagement and surroundings, $\chi^{2}(1, \mathrm{~N}=426)=3.94, \mathrm{p}=0.05$.

5. between social engagement and personal spaces, $\chi^{2}(1, \mathrm{~N}=426)=3.55, \mathrm{p}=0.06$.

6. between surroundings and personal spaces, $\chi 2(1, \mathrm{~N}=426)=0.85, \mathrm{p}=0.36$.

viii This university, founded in 1884, is 'situated between the mountains and the sea' in north Wales (The university website, 2017) and described as a 'Welsh university in the heart of Wales'. With a student population of 10,765 , it is one of the middle-ranked (39th) institutions (the Times Higher Education World University Rankings 2018) and achieved a Gold Award in the national Teaching Excellence Framework (TEF). This university is one of the UK's top 10 universities for student satisfaction according to the 2017 National Student Survey, where students value accommodation as the best in the UK (What Uni Student Choice Award, 2016). 